\title{
The usefulness of Tanita TBF-310 for body composition assessment in Judo athletes using a four-compartment molecular model as the reference method
}

\author{
(D) Christophe Domingos ${ }^{1}$ \\ id Catarina Nunes Matias ${ }^{1}$ \\ (D) Edilson Serpeloni Cyrino ${ }^{2}$ \\ (DLuís Bettencourt Sardinha ${ }^{1}$ \\ (i) Analiza Mónica Silva ${ }^{1}$
}

1. Exercise and Health Laboratory, CIPER, Faculdade de Motricidade Humana, Universidade Lisboa, Estrada da Costa, $1499-688$ Cruz-Quebrada, Portugal. 2. Laboratório de Metabolismo, Nutrição e Exercício, Centro de Educação Física e Esportes, Universidade Estadual de Londrina, Londrina, PR, Brasil.

http://dx.doi.org/10.1590/1806-9282.65.10.1283

\section{SUMMARY}

Body composition assessment at the molecular level is relevant for the athletic population and its association with high performance is well recognized. The four-compartment molecular model (4C) is the reference method for fat mass (FM) and fat-free mass (FFM) estimation. However, its implementation in a real context is not feasible. Coaches and athletes need practical body composition methods for body composition assessment, and the bioelectrical impedance analysis method (BIA) is usually seen as a useful alternative. The aim of this study was to test the validity of BIA (Tanita, TBF-310) to determine the FM and FFM of elite judo athletes. A total of 29 males were evaluated in a period of weight stability using the reference method (4C) and the alternative method (Tanita, TBF-310). Regarding the 4C method, total-body water was assessed by deuterium dilution, bone mineral by DXA, and body volume by air displacement plethysmography. The slops and intercepts differed from 1 (0.39 and 1.11) and 0 (4.24 and -6.41) for FM and FFM, respectively. FM from Tanita TBF-310 overestimated the 4C method by $0.2 \mathrm{~kg}$ although no differences were found for FFM. Tanita TBF-310 explained 21\% and $72 \%$ respectively in the estimation of absolute values of FM and FFM from the $4 C$ method. Limits of agreement were significant, varying from $-6.7 \mathrm{~kg}$ to $7.0 \mathrm{~kg}$ for FM and from $-8.9 \mathrm{~kg}$ to $7.5 \mathrm{~kg}$ for FFM. In conclusion, TBF-310 Tanita is not a valid alternative method for estimating body composition in highly trained judo athletes.

KEYWORDS: Bioelectrical impedance analysis; tanita TBF-310; 4 compartments model; fat mass; fat-free mass; body composition methods.

\author{
ABBREVIATIONS: \\ 2C - Two-compartment model \\ 4C - four-compartment model \\ ${ }^{2} \mathrm{H}_{2} \mathrm{O}$ - Deuterium oxide solution dose \\ BIA - Bioelectrical impedance analysis method \\ BMC - Bone mineral content \\ $\mathrm{BV}$ - Body volume \\ BW - Body weight \\ $\mathrm{CV}$ - Coefficient of variation \\ DFFM - Fat-free mass density
}
FFM - Fat-free mass
FM - Fat mass
M - Total-body mineral
Mo - Bone mineral
Ms - Total-body soft tissue mineral
SMOW - Standard mean ocean water
TBW - Total-body water
$\mathrm{TEM}^{2}$ - Squared technical errors of measurement
$\mathrm{VO}_{2 \max }-$ Maximum oxygen uptake 


\section{INTRODUCTION}

For athletic populations, body composition has an important role in performance regulation and training programs; that is even more relevant in sports in which weight can greatly affect the performance, or a target body weight needs to be achieved. Judo athletes frequently use dehydration techniques for weight loss since it is a quick way to achieve a target weight, a strategy that impairs performance ${ }^{1-4}$. The assessment of body composition in weight-sensitive sports, such as judo, using bioelectrical impedance analysis (BIA) is still relatively unexplored, and information is scarce in this area ${ }^{5}$.

BIA is a method based on a volumetric approach to estimate total-body water (TBW). Based on the assumption that fat-free mass (FFM) comprises $73.2 \%$ of water, the mass of this compartment can be calculated from TBW. Then, fat mass (FM) is obtained by subtracting FFM from the total-body mass. In athletes, the water fraction of FFM tends to have a high variability $^{6-10}$. The algorithms used by BIA devices to predict TBW do not take into account the variability of water fraction in the FFM compartment and also the variability of the remaining protein and mineral fractions. Different BIA manufactures and devices also use several different algorithms to estimate TBW and its associated calculation of FFM. Among several types of BIA equipment, foot-to-foot equipment has been used to assess body composition in highly active adults ${ }^{11-13}$. In a large sample of adults, including participants involved in regular sport practice ${ }^{\mathbf{1 4}}$, the foot-to-foot BIA equipment (TBF-310) presented higher reproducibility in fat mass determination ${ }^{\mathbf{1 1}}$. Another study involving lean and obese adults used the foot-to-foot BIA equipment (TBF-300A) and concluded that it was an accurate solution for lean but not obese adults when compared to bioimpedance spectroscopy ${ }^{12}$. Swartz et al ${ }^{13}$ used a sample of highly active adults and found that the 'adult' mode of a footto-foot BIA equipment (TBF-305) accurately estimated group \% body fat of individuals engaging in $>2.5 \mathrm{~h}$ aerobic activity/week, using hydrostatic weighing as the reference. Considering the studies above, using footto-foot BIA equipment in highly active adults did not use reference methods for determining the accuracy of body composition measures, specifically by using the reference method at the molecular level, i.e., the four-compartment model (4C model).

At the molecular level, multicompartment models, such as the four-compartment model (4C) take into consideration the variability of the main FFM components (water, protein, and minerals) and are considered the state of the art regarding FM and FFM assessment because they provide more accurate estimates of body composition than the other methods ${ }^{15}$.

The performance of the Tanita model TBF-310, a foot-to-foot device for body composition assessment of athletes, is still unknown. The aim of this study was to test the validity of BIA (Tanita, TBF-310) in the determination of FFM and FM in judo athletes using a 4C molecular method as a reference. We hypothesize that the Tanita TBF-310 it is a valid alternative in body composition estimation of judo athletes when compared to a $4 \mathrm{C}$ model.

\section{METHODS}

\section{Participants}

Twenty-nine male judo athletes from the Portuguese national team were evaluated during a period of weight stability. The inclusion criteria were as follows: 1 ) age of 18 years or over; 2 ) at least 5 years of training experience; 3 ) currently training at least $15 \mathrm{~h}$ per week; 4) a minimum technical level of 1rst degree black belt; 5) tested negative for doping; and 6) not taking any medications or dietary supplements.

Medical screening indicated no health limitations for study participation. All athletes were informed about the possible risks of the investigation before providing written informed consent to participate.

All procedures were approved by the Ethics Committee of the Faculty of Human Kinetics, University of Lisbon and conducted in accordance with the Declaration of Helsinki ${ }^{16}$.

\section{Experimental design}

Participants were national top-level judo athletes. Data collection was performed between September and October. The period of weight stability was considered the baseline phase with judo athletes performing their regular regimens of judo training, which typically consists of $2 \mathrm{~h}$ in the morning and $2 \mathrm{~h}$ in the evening. Two of the morning sessions were used for improving cardiorespiratory fitness and strength, while the other sessions consisted of judo-specific skills, drills, and randori (fighting practice) with varying intensity below and up to 90-95\% of maximum oxygen uptake $\left(\mathrm{VO}_{2 \max }\right)$, representing a target heart rate below and up to $185-190$ beats/min. 


\section{Body composition measurements}

Participants attended the laboratory after a 12-h fast and refrained from exercise, alcohol, or stimulant beverages for at least $15 \mathrm{~h}$. All measurements were carried out on the same morning. In brief, the procedures were as follows:

\section{Anthropometry}

Participants were weighed to the nearest $0.01 \mathrm{~kg}$ wearing a bathing suit without shoes on an electronic scale connected to the plethysmograph computer (BOD POD, COSMED, Rome, Italy). Height was measured to the nearest $0.1 \mathrm{~cm}$ with a stadiometer (Seca, Hamburg, Germany), according to the standardized procedures described elsewhere ${ }^{17}$.

\section{Hydration status}

To ensure all athletes were in a neutral hydration state during the period of weight stability, we checked if voided urine was pale yellow. We confirmed with the athletes that their first daily post-voiding body weight on the 3 days before the first visit did not change by more than $1 \%{ }^{18}$.

\section{Bioelectrical impedance analysis.}

Body composition was assessed using the Tanita Body Composition Analyser - model TBF-310 foot-tofoot (Tanita Corp., Tokyo, Japan) which provided a print-out of measured impedance and calculated FM and FFM. FFM hydration is assumed as a constant value of $73.2 \%$. The subjects were barefoot and wearing bathing suits for the evaluation. Based on the test-retest of 10 subjects, the coefficients of variation for both fat-free mass and fat mass were nearly $2 \%$.

\section{Four-compartment model}

A four-compartment (4C) model was used as the reference method with total-body soft tissue mineral (Ms) component estimated at 0.0129TBW ${ }^{19}$. The 4C model is described as follows:

$$
F M(k g)=2.748 B V-0.699 T B W+1.129 M o
$$$$
-2.051 B M(1)
$$

Where FM is fat mass, BV is body volume (L) assessed by air displacement plethysmograph, TBW is total body water $(\mathrm{kg})$ evaluated by the deuterium dilution technique, Mo is bone mineral $(\mathrm{kg})$ obtained by DXA, Ms is total body soft tissue mineral content $(\mathrm{kg})$, and BW is body weight $(\mathrm{kg})$.
Total body mineral (M) was calculated as:

$$
\mathrm{M}=\mathrm{Mo}+\mathrm{Ms}(3)
$$

Fat-free mass was calculated as body weight minus fat mass.

\section{Calculation of fat-free mass density}

FFM density (DFFM) was estimated from TBW, Mo, Ms, and protein (protein is equal to body weight minus fat mass, TBW, Mo, and Ms), contents of FFM (estimated as body weight minus FM from the 4C model) and their densities (0.9937, 2.982, 3.317, and $1.34 \mathrm{gcc}$ ) for TBW, Mo, Ms, and protein, respectively:

$D F F M=1 /[(T B W / D T B W)+(M o / D M o)+(M s / D M s)+$ (protein/Dprotein)] (4)

\section{Bone mineral}

Dual-energy X-ray absorptiometry (Scan Hologic Explorer-W, fan-beam densitometer, software QDR for Windows version 12.4; Hologic, Waltham, Massachusetts, USA) was used to measure bone mineral content (BMC). The scan positioning, acquisition, and analysis were standardized. Since bone mineral content represents ashed bone, BMC was converted to total body bone mineral (Mo) by multiplying it by $1.0436^{20}$. The coefficient of variation (CV), based on the test-retest of 10 participants, was $1.6 \%{ }^{21}$.

\section{Body volume}

Body volume was assessed by air displacement plethysmography (COSMED, Rome, Italy) as described elsewhere ${ }^{22}$. Body volume was computed based on the initial body volume corrected for thoracic gas volume and a surface area artifact computed automatically. The CV, based on the test-retest of 10 participants, was $0.5 \%{ }^{23}$.

\section{Total-body water}

Total-body water (TBW) was assessed by the deuterium dilution technique using a stable Hydra gas isotope ratio mass spectrometer (PDZ, Europa Scientific, UK). After a 12-h fast, an initial urine sample was collected and a deuterium oxide solution dose $\left({ }^{2} \mathrm{H}_{2} \mathrm{O}\right)$ of 99.9 atom \% D (Sigma-Aldrich Chemistry) at $0.1 \mathrm{~g} / \mathrm{kg}$ of body weight, diluted in $50 \mathrm{~mL}$ of tap water was immediately administered. After a 4-h equilibration period, a new urine sample was collected. Abundances of ${ }^{2} \mathrm{H}_{2} \mathrm{O}$ in dilutions of the isotope doses were analyzed. Urine 
and diluted dose samples were prepared for analysis using the equilibration technique of Scrimgeour and colleagues $^{24}$. The enrichments of equilibrated local water standards were calibrated against the standard mean ocean water (SMOW). Based on delta SMOW, total body water was estimated including a $4 \%$ correction due to the recognized amount corresponding to deuterium dilution in other compartments ${ }^{25}$. The $\mathrm{CV}$, based on the test-retest of 10 participants, was $1.3 \%{ }^{26}$.

\section{Propagation of measurement error}

In the present study, we selected air-displacement plethysmography to assess BV, DXA to estimate bone mineral, and BIA to estimate TBW. The propagation of measurement errors associated with the determination of BV, TBW, and bone mineral (Mo) can be calculated by assuming that the squared technical errors of measurement $\left(\mathrm{TEM}^{2}\right)$ are independent and additive. Accordingly:

TEM $=\left(T_{E M}^{2}\right.$ for effect of body volume determination on $\% F M+T E M^{2}$ for $T B W$ on $\% F M+T E M^{2}$ for MO on \% FM) $1^{0.5}$

So, using the equation above:

$$
T E M=\left[0.81^{2}+0.36^{2}+0.04^{2}\right] 1^{0.5}=0.89 \% F M
$$

The precision of the $4 \mathrm{C}$ model to determine FM was $\sim 1 \%$.

\section{Statistical analysis}

Data were analyzed with SPSS software for Windows version 22.0 (SPSS Inc., Chicago, IL). The comparison of group means was performed using paired-sample t-test and Wilcoxon test when normality was not verified. Comparison of group means with the reference population was made using one-sample t-test. Simple linear regression analysis was performed to calculate the relationship between fat-free mass estimated by the reference $4 \mathrm{C}$ model and from BIA. The concordance correlation coefficient analysis was performed according to $\operatorname{Lin}^{27}$ using the software MedCalc (Software MedCalc, Mariakerke, Belgium (2009)). The agreement between methods was assessed by the Bland-Altman method ${ }^{28}$, including the $95 \%$ limits of agreement. The correlation between the mean of the reference and the alternative method with the difference between both was used as an indication of proportional bias. Also, correlations between the differences between the methods and potential variables that could affect these differences were determined. For all tests, statistical significance was set at $\mathrm{p}<0.05$.

\section{RESULTS}

The variables representing demographic characteristics and body composition of participants are presented in Table 1.

TABLE 1. CHARACTERISTICS AND BODY COMPOSITION VARIABLES $(\mathrm{N}=29)$

\begin{tabular}{l|l|l} 
& Total $(\mathrm{n}=29)$ & \multirow{2}{*}{ Range } \\
\cline { 2 - 3 } & Mean $\pm \mathrm{SD}$ & \\
\hline Age $($ years $)$ & $23.1 \pm 3.4$ & $18-31$ \\
\hline Weight $(\mathrm{kg})$ & $73.5 \pm 8.4$ & $56.5-100.1$ \\
\hline Height $(\mathrm{cm})$ & $175.4 \pm 5.7$ & $165-188.7$ \\
\hline $\mathrm{BMI}\left(\mathrm{kg} / \mathrm{m}^{2}\right)$ & $24.0 \pm 2.6$ & $20.2-31.2$ \\
\hline $\mathrm{FM}_{4 \mathrm{C}}(\mathrm{kg})$ & $7.0 \pm 3.1$ & $2.9-16.7$ \\
\hline $\mathrm{FM}_{4 C}(\%)$ & $9.5 \pm 3.7$ & $3.7 \pm 20.6$ \\
\hline $\mathrm{FFM}_{4 C}(\mathrm{~kg})$ & $66.5 \pm 7.8$ & $51.2-89.7$ \\
\hline $\mathrm{FM}_{\text {Tanita }}(\mathrm{kg})^{\text {a }}$ & $7.2 \pm 3.6$ & $2.8-17.4$ \\
\hline $\mathrm{FM}_{\text {Tanita }}(\%)^{\text {a }}$ & $9.5 \pm 3.8$ & $4.1-20.4$ \\
\hline $\mathrm{FFM}_{\text {Tanita }}(\mathrm{kg})$ & $65.7 \pm 5.93$ & $52.8-82.8$ \\
\hline Water fraction $(\%)$ & $71.6 \pm 2.1$ & $68-77$ \\
\hline Bone mineral fraction $(\%)$ & $4.9 \pm 0.3$ & $4-5$ \\
\hline Soft mineral fraction $(\%)$ & $0.9 \pm 0.03$ & $1-1$ \\
\hline Residual fraction $(\%)$ & $22.6 \pm 2.4$ & $18-27$ \\
\hline FFM $_{D}\left(\mathrm{~g} / \mathrm{cm}^{3}\right)$ & $1.101 \pm 0.007$ & $1.085-1.112$ \\
\hline
\end{tabular}

Abbreviations: SD, standard deviations; BMI, body mass index; FM, Fat mass; FFM,

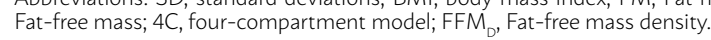

a Significantly different from the reference method, $p<0.05$

Tanita overestimated FM by $0.2 \pm 3.5 \mathrm{~kg}$ from the 4C model ( $\mathrm{p}=0.012)$ while for the FFM no differences were found between methods $(0.7 \pm 4.17 \mathrm{~kg})$ (Table 1$)$.

Table 2 shows the results related to the Tanita performance in the evaluation of FM and FFM by regression analysis and the concordance correlation coefficient.

TABLE 2. CRITERIA PERFORMANCE OF TANITA TBF310 IN THE ESTIMATION OF FM AND FFM FROM THE REFERENCE METHOD

\begin{tabular}{l|l|l|l|l|l|l|l} 
& $\mathrm{R}$ & SEE & Slope & Intercept & CCC & Precision & Accuracy \\
\hline & $(\mathrm{kg})$ & & & & & $(p)$ & $(\mathrm{Cb})$ \\
\hline $\begin{array}{c}\text { FM } \\
(\mathrm{kg})\end{array}$ & 0.46 & 2.75 & $0.39^{\mathrm{a}}$ & $4.24^{\mathrm{b}}$ & 0.45 & 0.46 & 0.98 \\
\hline $\begin{array}{c}\text { FFM } \\
(\mathrm{kg})\end{array}$ & 0.85 & 4.20 & $1.11^{\mathrm{a}}$ & -6.41 & 0.81 & 0.85 & 0.96 \\
\hline
\end{tabular}

Abbreviations: R, coefficient of correlation; SEE, standard error of estimation; CCC, concordance correlation coefficient; FM, Fat mass; FFM, Fat-free mass.

a Slope significantly different from $1, p<0.05$

${ }^{b}$ Intercept significantly different from $0, p<0.05$ 
The alternative method explained $21 \%$ and $72 \%$ of the absolute values observed in FM and FFM, respectively, from the reference method.

For both FM and FFM, the slops and the intercepts, differed from 1 and 0 , respectively.

Figure 1 displays the agreement between methods using the Bland-Altman technique. For FM and FFM, relatively large limits of agreement (95\% confidence intervals) were observed with an under-estimation of $-6.7 \mathrm{~kg}$ and $-8.8 \mathrm{~kg}$ or an over-estimation of $7.0 \mathrm{~kg}$ and $7.5 \mathrm{~kg}$, respectively for FM and FFM.

\section{DISCUSSION}

We evaluated the validity of Tanita TBF-310 for body composition estimation in elite judo athletes, using a $4 \mathrm{C}$ model as the reference method. Our findings indicate that this BIA device is not accurate for assessing body composition in highly trained athletes.

The present foot-to-foot BIA equipment, a simple and low-cost solution for body composition estimation in the field settings, has been used to assess fat and fat-free mass of highly active populations ${ }^{11-13}$ with acceptable accuracy, though not extended by our findings.

So far, no studies analyzed the Tanita model (TBF310) for determining body composition in athletes using the $4 \mathrm{C}$ model as criterion. Nevertheless, this foot-to-foot device was validated in other populations $^{29-31}$. In a cross-sectional study using DXA as the reference method, Beeson et al. found that Tanita TBF310 explained $86 \%$ and $93 \%$ of FM (\%) and FFM $(\mathrm{kg})$, respectively, in Hispanic diabetic participants but with large individual variability ${ }^{29}$. Using a cross-sectional design, Radley et al. reported that Tanita TBF-319 explained $94 \%$ and $83 \%$ of FM and FFM, respectively, in overweight and obese children with individual differences up to $11.0 \%$ for FM and $9.3 \mathrm{~kg}$ for FFM compared to $\mathrm{DXA}^{30}$. In a longitudinal study with a sample of overweight and obese women, the Tanita TBF-310 explained $77 \%$ and $14 \%$ of the variability in $\mathrm{FM}$ and FFM changes from a 4C model, along with wide limits of agreement ${ }^{31}$.

Compared to the aforementioned studies, Tanita TBF-310 showed poor validity, explaining $21 \%$ and $72 \%$ for FM and FFM, respectively, with a lack of agreement between methods and inaccuracies in estimating body composition at an individual level. It is important to underline that a $4 \mathrm{C}$ model was used as the criterion to validate the foot-to-foot BIA device. This state-ofthe-art method does not rely on assumptions in FM determination as it accounts for the variability of the FFM components, namely TBW, protein, and mineral.

Conversely, in 2C models using densitometric techniques, the FFM density is assumed to be constant at $1.1 \mathrm{~g} / \mathrm{cm}^{3}$ by considering that a stable contribution of the main FFM components is observed ${ }^{32}$. We observed that TBW, protein, and mineral fractions of the FFM were similar to those observed on cadaver analysis ${ }^{33}$. Brozek et al ${ }^{32}$ referred $5.6 \%$ of Mo is FFM, and $1.2 \%$ of $\mathrm{Ms}$ is $\mathrm{FFM}^{32}$. We obtained values of $4.8 \%$ and $0.92 \%$, respectively, for Mo and Ms FFM fractions. For protein, the assumed contribution is $19.4 \%$, but a higher percentage was found in this study $22.6 \%$. In the majority of mammals, TBW/FFM is constant at $73.2 \% \pm 0.036^{33}$, but in our study we found that athletes

FIGURE 1. BLAND-ALTMAN ANALYSIS OF THE DIFFERENCES BETWEEN TANITA TBF-310 AND THE 4C MODEL FOR FM AND FFM ESTIMATION. THE SOLID MIDDLE LINE REPRESENTS THE MEAN DIFFERENCES BETWEEN ABSOLUTE FAT MASS (FM) AND FAT-FREE MASS (FFM) FROM TANITA TBF-310 AND THE FOUR-COMPONENT MODEL (4-C); THE UPPER AND LOWER DASHED LINES REPRESENT \pm 2 SD FROM THE MEAN, I.E. $95 \%$ LIMITS OF AGREEMENT ( \pm 1.96 SD).
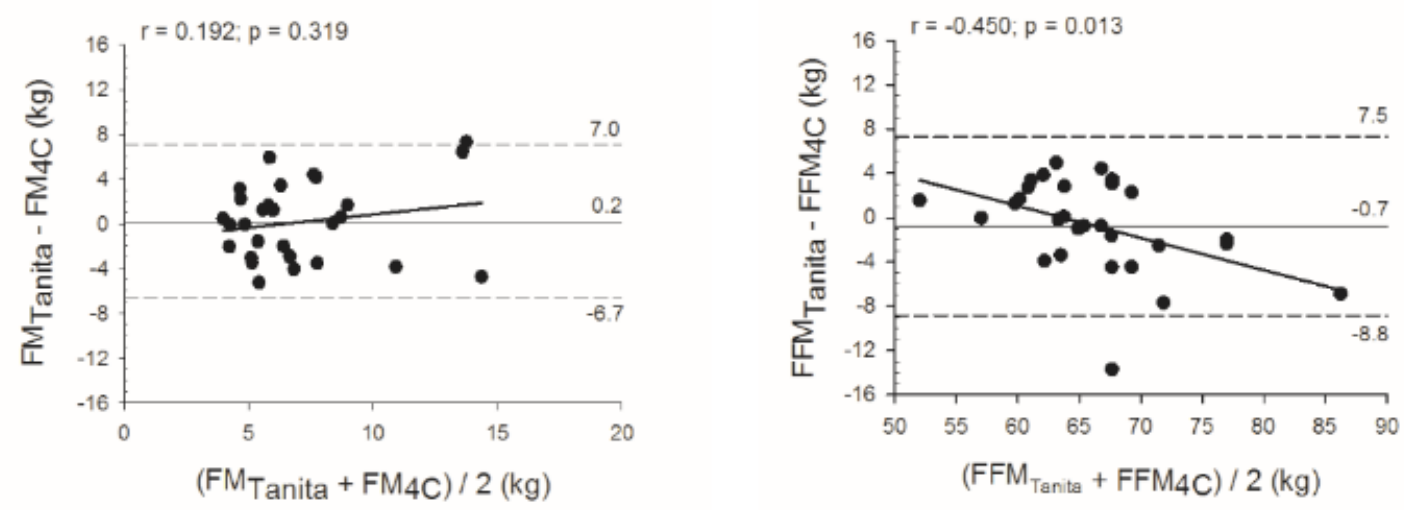
showed a mean value of $71.5 \% \pm 2.1 \%$. Therefore, using hydrometric techniques to estimate FFM based on the assumed value of $73.2 \%$, an overestimation of FM and an underestimation of FFM would be expected. These results indicate that the assumption of a stable FFM composition and density is not appropriate in highly trained judo athletes. In fact, densitometric and hydrometric techniques may compromise body composition estimation in this population.

The use of the 4C model is a major strength of this study, as this method is considered the "state of the art" to determine the FM and FFM at the molecular level. The 4C model accounts for the variability of the FFM molecular components thus avoiding assumptions that may not be valid for highly trained athletes.

A few limitations of this study should be highlighted, namely its external validity as results are not generalized for females, non-athletic population, and other devices/models. This study did not assess the validity of this equipment in determining longitudinal changes in body composition. It is also important to mention that the validity of the equipment was tested during a period of weight stability in judo athletes and therefore it is unknown if a similar accuracy would be found if these athletes were assessed prior competition when a target body weight would be required.

Many laboratories and clinical centers still use the Tanita TBF-310 equipment. The point of this validation was to demonstrate the usefulness of this equipment for estimating body composition in athletes whose weight management is determinant. Based on the findings, this equipment provided inaccurate estimations of fat and fat-free mass and must not be used for assessing body composition in elite judo athletes.

\section{CONCLUSION}

Considering all the performance criteria, our findings revealed that Tanita TBF-310 is not a valid alternative in body composition estimation of judo athletes when compared to a $4 \mathrm{C}$ model. The larger individual variability observed limits its accuracy at an individual level. Thus, Tanita TBF-310 should not be used in judo athletes to assess and monitor body composition over the season as the errors observed when using this device may compromise athletic health and performance.

\section{Acknowledgments}

We would like to express our gratitude to the athletes for their time and effort. This work was supported by the Portuguese Foundation for Science and Technology (grant: PTDC/DES/69495/2006).

\section{Conflict of interest}

None of the authors had a conflict of interest in any company or organization sponsoring this study.

\section{Authors Contributions}

CD: responsible for data pooling, screening, analysis, and manuscript writing; CM: responsible for data analysis and data collection; CE: responsible for manuscript revision and advice; LS: responsible for manuscript revision and advice and AMS: responsible for manuscript writing and provided administrative support, supervision, and advice.

\section{RESUMO}

A avaliação da composição corporal ao nível molecular é relevante para a população esportiva e sua associação com o alto rendimento é bem reconhecida. O modelo molecular a quatro compartimentos (4C) é o método de referência para as estimativas de massa gorda (MG) e massa livre de gordura (MLG). No entanto, sua implementação no contexto real não é viável. Técnicos e atletas precisam de métodos práticos de composição corporal para a avaliação da composição corporal e o método de análise de impedância bioelétrica (BIA) é geralmente visto como uma alternativa útil. O objetivo deste estudo foi testar a validade da BIA (Tanita, TBF-310) na determinação de MG e MLG em atletas de elite de judô. Um total de 29 atletas masculinos foi avaliado em um período de estabilidade de peso usando o método de referência (4C) e o método alternativo (Tanita, TBF-310). Em relação ao método a 4C, a água corporal total foi avaliada pela diluição de deutério, mineral ósseo por DXA e volume corporal por pletismografia por deslocamento de ar. Os declives e interceções diferiram de 1 (0,39 e 1,11) e O (4,24 e -6,41) para MG e MLG, respectivamente. A MG da Tanita TBF-310 superestimou o método 4C em 0,2 kg, embora não tenham sido encontradas diferenças para MLG. A Tanita TBF-310 explicou 21\% e 72\%, respectivamente, na estimativa dos valores absolutos de MG e MLG do método a 4C. Os limites de concordância foram grandes, variando de $-6,7 \mathrm{~kg}$ a 7,0 kg para MG e de -8,9 kg a 7,5 kg para MLG. Em conclusão, a TBF-310 Tanita não é um método alternativo válido para estimar a composição corporal em judocas altamente treinados.

PALAVRAS-CHAVE: Análise por impedância bioelétrica. Tanita TBF-310. Modelo a quatro compartimentos. Massa gorda. Massa livre de gordura. Métodos de avaliação de composição corporal. 


\section{REFERENCES}

1. Casa, D.J., et al., National athletic trainers' association position statement: fluid replacement for athletes. J Athl Train, 2000. 35(2): p. 212-24.

2. Armstrong, L.E., et al., Human hydration indices: acute and longitudinal reference values. Int J Sport Nutr Exerc Metab, 2010. 20(2): p. 145-53.

3. Silva, A.M., et al., Relationship between changes in total-body water and fluid distribution with maximal forearm strength in elite judo athletes. J Strength Cond Res, 2011. 25(9): p. 2488-95.

4. Silva, A.M., et al., Body composition and power changes in elite judo athletes. Int J Sports Med, 2010. 31(10): p. 737-41.

5. Ackland, T.R., et al., Current status of body composition assessment in sport: review and position statement on behalf of the ad hoc research working group on body composition health and performance, under the auspices of the I.O.C. Medical Commission. Sports Med, 2012. 42(3): p. 227-49.

6. Silva, A.M., et al., Body fat measurement in adolescent athletes: multicompartment molecular model comparison. Eur | Clin Nutr, 2006. 60(8): p. 955-64.

7. Quiterio, A.L., et al., Total body water measurements in adolescent athletes: a comparison of six field methods with deuterium dilution. J Strength Cond Res, 2009. 23(4): p. 1225-37.

8. Santos, D.A., et al., Accuracy of DXA in estimating body composition changes in elite athletes using a four compartment model as the reference method. Nutrition \& Metabolism, 2010. 7(1): p. 22.

9. Santos, D.A., et al., Association of basketball season with body composition in elite junior players. J Sports Med Phys Fitness, 2014. 54(2): p. 162-73.

10. Silva, A.M., et al., Total Energy Expenditure Assessment in Elite Junior Basketball Players: A Validation Study Using Doubly Labeled Water. Journal of Strength and Conditioning Research, 2013. 27(7): p. 1920-1927.

11. Lafay, L., et al., Determinants and nature of dietary underreporting in a free-living population: the Fleurbaix Laventie Ville Sante (FLVS) Study. Int J Obes Relat Metab Disord, 1997. 21(7): p. 567-73.

12. Gagnon, C., et al., Comparison of foot-to-foot and hand-to-foot bioelectrical impedance methods in a population with a wide range of body mass indices. Metab Syndr Relat Disord, 2010. 8(5): p. 437-41.

13. Swartz, A.M., et al., Evaluation of a foot-to-foot bioelectrical impedance analyser in highly active, moderately active and less active young men. $\mathrm{Br}$ Nutr, 2002. 88(2): p. 205-10.

14. Kettaneh, A., et al., Reliability of bioimpedance analysis compared with other adiposity measurements in children: the FLVS II Study. Diabetes Metab, 2005. 31(6): p. 534-41.

15. Wang, Z.M., et al., Six-compartment body composition model: intermethod comparisons of total body fat measurement. Int j Obes Relat Metab Disord, 1998. 22(4): p. 329-37.

16. World Medical Association, World Medical Association Declaration of Helsinki: ethical principles for medical research involving human subjects. JAMA, 2013. 310(20): p. 2191-4

17. Lohman, T., A. Roache, and R. Martorell, Anthropometric Standardization Reference Manual. Medicine \& Science in Sports \& Exercise, 1992. 24(8): p. 952.
18. Casa, D.J., P.M. Clarkson, and W.O. Roberts, American College of Sports Medicine roundtable on hydration and physical activity: consensus statements. Curr Sports Med Rep, 2005. 4(3): p. 115-27.

19. Wang, Z., et al., Multicomponent methods: evaluation of new and traditional soft tissue mineral models by in vivo neutron activation analysis. Am | Clin Nutr, 2002. 76(5): p. 968-74.

20. Heymsfield, S.B., et al., Body composition in elderly subjects: a critical appraisal of clinical methodology. Am J Clin Nutr, 1989. 50(5 Suppl): p. 1167-75; discussion 1231-5.

21. Silva, A.M., et al., Relationship between changes in total-body water and fluid distribution with maximal forearm strength in elite judo athletes. The Journal of Strength \& Conditioning Research, 2011. 25(9): p. 2488-2495.

22. Silva, A.M., et al., Are skinfold-based models accurate and suitable for assessing changes in body composition in highly trained athletes? J Strength Cond Res, 2009. 23(6): p. 1688-96.

23. Santos, D.A., et al., Accuracy of DXA in estimating body composition changes in elite athletes using a four compartment model as the reference method. Nutrition \& metabolism, 2010. 7(1): p. 1

24. Scrimgeour, C.M., et al., A simplified method for deuterium/hydrogen isotope ratio measurements on water samples of biological origin. Biol Mass Spectrom, 1993. 22(7): p. 383-7.

25. Schoeller, D., Hydrometry, in Human body composition, L.T. Heymsfield SB, Wang Z, Going S, editors., Editor. 2005: Champaign, IL: Human Kinetics. p. 35-49.

26. Matias, C.N., et al., Is bioelectrical impedance spectroscopy accurate in estimating total body water and its compartments in elite athletes? Annals of human biology, 2013. 40(2): p. 152-156.

27. Lawrence, I. and K. Lin, A concordance correlation coefficient to evaluate reproducibility. Biometrics, 1989: p. 255-268.

28. Bland, J.M. and D. Altman, Statistical methods for assessing agreement between two methods of clinical measurement. The lancet, 1986. 327(8476): p. 307-310

29. Beeson, W.L., et al., Comparison of body composition by bioelectrical impedance analysis and dual-energy X-ray absorptiometry in Hispanic diabetics. Int | Body Compos Res, 2010. 8(2): p. 45-50.

30. Radley, D., et al., Validity of foot-to-foot bio-electrical impedance analysis body composition estimates in overweight and obese children. Int J Body Compos Res, 2009. 7(1): p. 15-20.

31. Minderico, C.S., et al., Usefulness of different techniques for measuring body composition changes during weight loss in overweight and obese women. Br J Nutr, 2008. 99(2): p. 432-41.

32. Brozek, |., et al., Densitometric Analysis of Body Composition: Revision of Some Quantitative Assumptions. Ann N Y Acad Sci, 1963. 110: p. 113-40.

33. Wang, Z., et al., Hydration of fat-free body mass: new physiological modeling approach. Am J Physiol, 1999. 276(6 Pt 1): p. E995-E1003. 